\section{Human-Robot Interaction in Industrial Working Environments}

\author{
Results from a Start-up Project
}

\author{
by António B. Moniz, ITAS
}

The social dimension of worker-robot interaction in industry is becoming a decisive aspect of robotics development. Many problems and difficulties of robotics research are not only related to technical issues but framed by social aspects. Human-robot interaction (HRI) as a specific research field of robotics tackles this issue. The debate on social involvement in HRI design of a few decades ago must be re-opened. A start-up project was initiated in 2012 at Karlsruhe Institute of Technology (KIT) to define a new research field and establish a conceptual framework on HRI. It was related to recent developments in the manufacturing industry and professional service robotics. The aim was to cooperate with other research teams to establish an expert network in this field. Special focus was placed on the design of work organisation models and issues of robotics technology design for worker (or operator) and robot interaction. In the current paper we present the most important conclusions from these research activities.

Social involvement in HRI has ceased to be a major topic of debate in the scientific arena. The social importance of the application of robotics in several spheres of human life became crucial, but not on the social criteria of robotic systems design. Early Technology Assessment studies, like the OTA study on "Social Impacts of Robotics" in 1982, show how deeply the discussion was rooted in that decade. Especially in the field of industrial sociology, many studies were carried out in the 1980's when automated technology was widely introduced in the manufacturing industry (Braverman, 1974; Corbett et al. 1991; Fischer/Lehrl 1991; Besselaar et al. 1991; European Commission 1997; Ennals/Gustavsen 1999; Brödner/Latniak 2002). Most studies investigated the increased complexity of technical systems and the implications of automated systems in terms of labour market changes, qualification changes and deskilling processes. Similar studies are not being carried out today. However, there is an obvious need to develop social sciences studies on the relation of humans to technology.

\section{Topicality of the Subject}

Human operator/robot interaction has gained relevance with increasingly complex work systems using robotic systems at the shop floor. However, this approach must be extended to social aspects of working, such as those related to the emergence of new competences, skills and new training needs, and to productivity and workplace environment (Kiesler/Hinds 2004; Jara et al. 2005; Kochan 2006; Lenz et al. 2008; De Santis et al. 2008).

Many recently developed concepts are related to "technology density", distributed decision making, cooperation, feedback, and complex work (Colombo et al. 2006; Hinds et al. 2004). Not all are related to the human-robot co-working systems dimension mentioned above but rather centre on technical interfaces, improved sensors and ergonomic design. We can also observe an increasing anthropomorphisation of machines (robots), raising new problems (Mayer et al. 2012). Cooperation is a new concept under development, as well as social interaction. Few concepts as feedback can be considered as a relevant concept in Complex Integrated Manufacturing Systems (CIMS), as for example described by Wrede et al. (2010) and Mayer et al. (2012). New concepts on human-machine co-working are not necessarily related to CIMS but usually only focus on humanoid robotics research and applications in health care. However, they have an increasing impact on future working systems - not only in the manufacturing sector. They will be relevant in the sectors of mining, underwater, professional services, agriculture, aerospace, and others. New studies assessing the attitudes towards robots or the workload in HRI can provide further empirical evidence on co-working concepts. Some of these new concepts are related to language processing (Akan et al., 2011). Especially in the field of manufacturing and professional use of robotics, the use of natural language for programming will become relevant. Haptics is less important in manufacturing but is particularly relevant to safety issues.

With a more intensive use of industrial robots and increased involvement of human operators, in- 
tuitive programming is becoming a very important topic of manufacturing applications, both for robot manufacturers and researchers (Thrun 2004).

\section{Different Approaches to HRI Design?}

Technology design (robots, system integration, software) does not specifically consider organisational dimensions (Bernstein et al. 2007; Moniz 2012). This conclusion can be drawn because technical innovations usually bring surprises when introduced in a real industrial environment. These technological innovations can very seldom be applied as they were designed and prepared for. If the organisational dimensions were included, problems could be easily anticipated and the levels of acceptance might increase. These systems are usually not designed with regard to the working groups or individuals using them. They are designed to comply with technical demands or standards. Here we can find some differences between the Japanese approaches and the Western ones. Why? One of the reasons is that Japanese companies and management systems use quality control as a key tool to improve their markets and products. That means all details must be anticipated and strategies for system improvement set out. The details must include job design (ergonomics, configuration of training and adapted skills) and task organisation. Under such conditions, the introduction of technical innovations in Japan is accompanied by fewer unexpected events and has higher acceptance.

However, this has not been subject of research yet. Industrial sociology has more focused on the macro- and meso-levels than on the micro- and workplace levels. However, Constructive Technology Assessment (CTA) aims to take account of the organisational dimension, once it approaches a more comprehensive process of decision making in emergent technologies (Decker/Ladikas 2004). Therefore, the anthropocentrism of technological design is state of the art in terms of the humanrobot interaction concept: it integrates technology design and social needs. In other words, in the design of HRI systems special consideration is given to the human dimension and not only to the robot specificities (Kiesler/Hinds 2004). In particular, technology design considers social dimensions related to safety issues, e.g. regarding the legal framework and the need for wide acceptance. In a few cases, employment factors and even ethical aspects are included. One of the reasons why these dimensions are not integrated in the technology design may be the education/training profiles of the designers (developing almost exclusively technocentric approaches). Here one can also find differences between the Japanese and Western approaches. In Japan, the trend is to use more intensively robots in manufacturing, resulting in increasing interaction with robots in this sector.

In general, the workplace design with robots requires different skills of human operators. In this sense, anticipation, planning and risk evaluation are new training needs (Heise 1989; Cypher 1993).

The workplace design with robots also implies different concepts of shared responsibility of human operators. A robot is a more dangerous tool/machine provided with autonomous reaction capabilities.

The final responsibility for action should always remain with the humans (e.g. Thomas 2011; Pfeiffer 2007; Yanco/Drury 2002). This does not mean that the responsibility lies solely with the human operators. Not "solely". But the human operators (shop floor workers, for example) should acknowledge responsibility if they have received appropriate training. The design of work organisation must consider the learning process to allocate responsibility appropriately. Operators can be responsible for their actions if they are involved in the work process. The coordinators of human operators have a coordination responsibility and should share it with their group members (direct workers). Thus, the concept of responsibility is even more important with autonomous systems.

Although it seems contradictory, human responsibility increases with the growing autonomy of automated systems. When a problem (or an unexpected event) occurs, the operators should be able to stop the robot operation and contribute to solving the problem. They must also know the consequences of stopping or not stopping the system. Assessment capabilities are needed here (Shah et al. 2008; Moniz 2012). And when a problem (unexpected event) occurs, robot operation should not be self-regulated. Intervention by the operator is always required. Humans should be able to intervene whenever necessary, also for safety reasons. In this respect, some of the most important inno- 
vations in operator-robot interaction are, possibly, enhanced communication options. The use of tacit knowledge to improve the operator-robot interaction also plays a major role here.

\section{Results: Key Challenges of HRI}

The main challenge in HRI research is to develop multi-agent decision-making processes. Such development should take account of the importance of tacit knowledge and worker experience. Interaction with safety is another key challenge (Kaiser 1994). In the manufacturing environment, another problem is how to integrate the element of complex tasks organisation, including several workers, different working stations, as well as their interrelations, with the increased complexity of decisions. From this perspective, new forms of work organisation in manufacturing (task enrichment, job rotation, semi-autonomous workgroups) should be considered in the HRI design (Eason 1996; Ennals/Gustavsen 1999; Moniz 2007).

To conclude, technology used in the manufacturing industry receives new inputs from research on other sectors (services, logistics, health), and in the field of HRI there have been significant developments in the last years. Automation models are transferred to other sectors as well (food production, agriculture, and mining). In general one can say that industrial organisation models are also applied to services. At the same time, the need for an interdisciplinary approach to industrial robotics design is evident (Prassler et al. 2005; Ribeiro/ Barata, 2006; Das/Jayaram 2007; Heyer 2010). It is no longer merely an issue for computer scientists or electronic engineers. The need to include social scientists, policy makers, legal and ethical experts is becoming crucial for a successful implementation strategy. The analysis of HRI in the manufacturing sector requires further empirical evidence on the micro-level. Social science studies on workplace changes can be benchmarks for improving quality standards and market sustainability.

All aims of the IR@MI project were achieved, including:

- To contribute to a national research network of social scientists in the field of industrial and professional robotics. The preparation and organisation of the workshop was the most im- portant initial step to build up such network. The effect was larger than expected. Several researchers from other countries are also interested to step in.

- To gain insights in research on robotics in the manufacturing industry and to transfer the results to other working fields (e.g. service robotics in health care), and vice versa. The review of literature has shown that such transfer is already practiced. The presentations in the workshop also revealed the exchange of technologies across the different application fields. This could be a subject for further research.

- To contribute to linking the KIT research areas "Humans and Technology" (MuT) and "Anthropomatics and Robotics" (AuR) in the field of manufacturing and production applications. The project has already taken an important step in this direction. In addition to the workshop that brought together spokespersons from those research areas (Bettina Krings and Martin Fischer for the MuT topic "Work and Technology", and Tamim Asfour for AuR topic "Anthropomatics and Robotics"), it is intended to prepare common KIT proposals focusing in such application sectors.

- To identify relevant research questions related to the development of safer robot systems in close human-machine interaction on the manufacturing shop floor. As a first step, a literature review was performed. As a second one, the workshop was held including members of the Institut für Arbeitsschutz der Deutschen Gesetzlichen Unfallversicherung (IFA). One outcome of the workshop was the decision to prepare common articles on the identified issues.

- To investigate the transferability of results to other fields where the introduction of robotics is planned (health care, agriculture, mining, underwater, logistics, orbital and planetary operations, inspection, disaster management, surgery, etc.). The study of robotic applications and their social implications provided clear evidence of this transferability. The main research questions were related to industrial applications. But it has become clear that many research findings are of interest to many other types of applications. The research network to follow will also focus on these possibilities and processes. 
- To prepare the basis for a strategic research agenda for KIT in the field of social implications of robotics and autonomous systems. The collection of data and establishment of a network are the initial steps in the development of such an agenda.

\section{Acknowledgment}

The author is grateful for the support provided by ITAS at KIT, Germany, and by the head of the ITAS Research Unit on Innovation Processes and Impacts of Technology Michael Decker.

\section{References}

Akan, B.; Ameri, A.; Çürüklü, B. et al., 2011: Intuitive Industrial Robot Programming Through Incremental Multimodal Language and Augmented Reality. IEEE International Conference on Robotics and Automation, Shanghai

Bernstein, D.; Crowley, K.; Nourbakhsh, I., 2007: Working with a robot: Exploring relationship potential in human-robot systems. In: Interaction Studies 8/3 (2007), pp. 465-482

Besselaar, P.; Clement, A.; Järvinen, P. (eds.), 1991: Information System, Work and Organization Design. Amsterdam

Braverman, H., 1974: Labor and Monopoly Capital: The Degradation of Work in the Twentieth Century. Monthly Review Press

Brödner, P.; Latniak, E., 2002: Sources of Innovation and Competitiveness: National Programmes Supporting the Development of Work Organisation. Report to DG Employment and Social Affairs. Gelsenkirchen, p. 7

Colombo, D.; Dallefrate, D.; Tosatti, L.M., 2006: PC Based Control Systems For Compliance Control and Intuitive Programming of Industrial Robots. SME Robot, ITIA, Milan; http://www.smerobot.org/08_scientific_papers/\#2006 (download 25.11.12)

Corbett, J.M.; Rasmussen, L.B.; Rauner, F., 1991: Crossing the Border. The Social and Engineering Design of Computer Integrated Manufacturing Systems. London

Cypher, A.I., 1993: Watch what I do: Programming by Demonstration. Cambridge, MA

Das, A.; Jayaram, J., 2007: Socio-technical Perspective on Manufacturing System Synergies.In: International Journal of Production Research 45/1, 169-205

De Santis, A.; Siciliano, B.; De Luca, A. et al., 2008: An Atlas of Physical Human-Robot Interaction. In: Mechanism and Machine Theory 43, pp. 253-270
Decker, M.; Ladikas, M. (eds.), 2004: Bridges Between Science, Society and Policy: Technology Assessment - Methods and Impacts. Berlin

Eason, K.D., 1996: Representing Socio-technical Systems Options in the Development of New Forms of Work Organization. In: European Journal of Work Organizational Psychology 5 (1996), pp. 399-420

Ennals, R.; Gustavsen, B., 1999: Work Organisation and Europe as a Development Coalition. Amsterdam

European Commission, 1997: Green Paper on "Partnership for a new Organisation of Work" (COM(97)128). Luxembourg

Fischer M.; Lehrl, W., 1991: Industrieroboter - Entwicklung und Anwendung im Kontext von Politik, Arbeit, Technik und Bildung. Bremen

Heise, R., 1989: Demonstration Instead of Programming: Focusing Attention in Robot Task Acquisition. Research report no. 89/360/22, Department of Computer Science, University of Calgary

Heyer, C., 2010: Human-Robot Interaction and Future Industrial Robotics Applications. IEEE/RSJ International Conference on Intelligent Robots and Systems. Taipei

Hinds, P.J.; Roberts, T.L.; Jones, H., 2004: Whose Job is it Anyway? A study of Human-Robot Interaction in a Collaborative Task. In: Human-Computer Interaction 19 (2004), pp. 151-181

Jara, C.A.; Candelas, F.A.; Gil, P. et al., 2005: An Augmented Reality Interface for Training Robotics Through the Web. In: Communication, pp. 189-194

Kaiser, M., 1994: A Framework for the Generation of Robot Controllers from Examples. In: 10th ISPE/ IFAC International Conference on CAD/CAM, Robotics and Factories of the Future. Ottawa

Kiesler, S.; Hinds, P., 2004: Introduction to this Special Issue on Human-Robot Interaction. In: HumanComputer Interaction 19 (2004), pp. 1-8

Kochan, A., 2006: Robots and Operators Work Handin Hand. In: Industrial Robot: An International Journal 33/6 (2006), pp. 422-424

Lenz, C.; Nair, S.; Rickert, M. et al., 2008: Joint-action for Humans and Industrial Robots for Assembly Tasks. In: Proceedings of RO-MAN 2008. The 17th IEEE International Symposium on Robot and Human Interactive Communication

Mayer, M.; Odenthal, B.; Faber, M. et al., 2012: Cognitive Engineering of Automated Assembly Processes. In: Human Factors and Ergonomics in Manufacturing \& Service Industries (2012), pp.1-21, DOI:10.1002/ hfm. 20390 
Moniz, A., 2007: The Collaborative Work Concept and the Information Systems Support: Perspectives for and from Manufacturing Industry. In: Technikfolgenabschätzung - Theorie und Praxis 16/2 (2007), pp. 49-57 Moniz, A., 2012: Anthropocentric-based Robotic and Autonomous Systems: Assessment for New Organisational Options. In: Decker, M.; Gutmann, M.: Robo- and Informationethics: Some Fundamentals. Zurich, pp. 123-157

Pfeiffer, S., 2007: Montage und Erfahrung. Mering

Prassler, E.; Lawitzky, G.; Stopp, A. et al. (eds.), 2005: Advances in Human-Robot Interaction. Berlin

Ribeiro, L.; Barata, J., 2006: New Shop Floor Control Approaches for Virtual Enterprises. In: Enterprise and Work Innovation Studies 2 (2006), pp. 25-32

Shah, J.A.; Saleh, J.H.; Hoffman, J.A., 2008: Analytical Basis for Evaluating the Effect of Unplanned Interventions on the Effectiveness of a Human-robot System. In: Reliability Engineering and System Safety 93 (2008), pp. 1280-1286

Thomas, C.; Busch, F.; Kuhlenkoetter, B. et al., 2011: Process and Human Safety in Human-Robot-Interaction - A Hybrid Assistance System for Welding Applications. In: Jeschke, S.; Liu, H.; Schilberg, D. (eds.): Intelligent Robotics and Applications. Proceedings of the 4th International Conference on Intelligent Robotics and Applications (ICIRA2011) 6.-9.12., Aachen. Berlin, pp. 112-121

Thrun, S., 2004: Toward a Framework for Humanrobot Interaction. In: Human-Computer Interaction 19/1 (2004), pp. 9-24

Yanco, H.A.; Drury, J.L., 2002: A Taxonomy for Human-robot Interaction. In: Proceedings of the AAAI Fall Symposium on Human-Robot Interaction, November 2002, Falmouth, MA. AAAI Technical Report FS-02-03, pp. 111-119

Wrede, B.; Kopp, S.; Rohlfing, K. et al., 2010: Appropriate Feedback in Asymmetric Interactions. In: Journal of Pragmatics 42/9 (2010), pp. 2369-2384

\section{Contact}

Prof. Dr. António Brandão Moniz

Institute for Technology Assessment and Systems

Analysis (ITAS)

Karlsruhe Institute of Technology (KIT)

Karlstraße 11, 76133 Karlsruhe

Phone: +49 (0) 721 / 608 - 24189

Email: antonio.moniz@kit.edu

\section{The ONLIFE Initiative - A Con- cept Reengineering Exercise}

\author{
by Judith Simon, ITAS
}

The deployment of information and communication technologies (ICTs) and their uptake by society affect radically the human condition, insofar as it modifies our relationships to ourselves, to others and to the world. With an unusual project design - the ONLIFE Initiative - the European Commission aimed at facilitating a broad reflection on future European policies. In this initiative, an interdisciplinary group of 13 scholars discussed the impact of information and communication technologies on our lives with a special emphasis on policy-relevant consequences of ICT-related developments. The results of their collective work are the ONLIFE Manifesto as well as individual contributions on the following four topics: Hyperconnectivity; Identity, Selfhood and Attention; Complexity, Responsibility and Governance; and the Public Sphere in a Computational Era. The results were publicly presented and discussed in Brussels on February 8, 2013. While this event in Brussels marked the end of the oneyear project, the name "Inaugural Event" already indicates that it was intended as a starting point for a wider discussion.

\section{Background}

In February 2012, the European Commission (DG Connect) launched "The ONLIFE Initiative - a Concept Reengineering Exercise" within the context of the Digital Agenda for Europe. Initiated by Nicole Dewandre of the EC and chaired by Luciano Floridi (University of Oxford/Hertfortshire), an interdisciplinary group of 13 scholars was invited to discuss the impact of information and communication technologies (ICTs) on our lives. Of particular concern were the policy-relevant consequences of ICT-related developments, e.g. changes with respect to notions of public space or new expectations towards public authorities resulting from the digital transition that characterizes our contemporary lifeworld. As the subtitle "Concept Reengineering Exercise" indi-

\section{$\langle\gg$}

